\title{
DELÍRIOS PERSECUTÓRIOS: UMA DESCRIÇÃO DAS TEORIAS E DE ESTUDOS EMPÍRICOS
}

\author{
Sara Sigmaringa Melo ${ }^{1}$
}

Resumo: Nas últimas duas décadas, a conceptualização das ideias delirantes, em geral, e dos delírios persecutórios, em particular, tem sido alvo de grande controvérsia. $\mathrm{O}$ presente artigo procura sumarizar e integrar a literatura existente acerca deste tema, começando por descrever brevemente algumas teorias inicialmente propostas para a explicação da paranóia, passando, de seguida, a uma descrição mais detalhada, com base em estudos realizados, das duas mais recentes propostas explicativas para os delírios persecutórios. Estas são a teoria de Trower e Chadwick (1995) e o modelo de Auto-Representação Atribucional sugerido por Bentall et al. (2001).

Será necessário que mais investigações sejam conduzidas, tendo em conta o dinamismo das crenças delirantes, de forma a que seja possível alcançar uma compreensão mais concertada do desenvolvimento e manutenção da paranóia.

Palavras-chave: paranóia, auto-estima, cognição social e dinamismo.

Persecutory delusions: a review of theories and evidence based studies (Abstract): The account for delusional beliefs, particularly persecutory beliefs, has been at the centre of much controversy over the last two decades. The present paper summarizes and integrates the existing literature on this topic and starts by briefly describing the first few theories that explained paranoia, moving later to a more detailed evidence based description of the two most recent accounts for paranoia. These are Trower and Chadwick's theory (1995) and Bentall et al.'s (2001) Attribution-Self-Representation model.

More studies looking further into the dynamics of delusional beliefs are needed to utterly understand both the development and maintenance of paranoia.

Key-words: paranoia, self-esteem, social-cognition and dynamism.

\footnotetext{
${ }^{1} \mathrm{PhD}$ student, School of Psychological Sciences, The University of Manchester PSICOLOGIA, Vol. XX (2), 2006, Edições Colibri, Lisboa, pp. 187-201
} 
De uma forma geral, no senso comum, a esquizofrenia corresponde a um quadro clínico altamente incapacitante e devastador, sendo as pessoas que dela padecem grandemente estigmatizadas. Apesar deste cenário catastrófico que nos foi deixado pelas primeiras definições de Kraepelin e que, ainda hoje, tão comummente se traça em relação à esquizofrenia, na realidade, esta doença já não tem contornos tão nefastos quanto antigamente acontecia (Carpenter \& Strauss, 1991).

Em verdade, desde os anos 50 que, com a introdução no mercado dos primeiros psicofármacos antipsicóticos (neurolépticos), foi possível controlar alguma da sintomatologia habitualmente encontrada na síndrome esquizofrénica. Até então, os tratamentos de que se dispunha passavam pela quase completa sedação dos pacientes (por exemplo, insulinoterapia). Além disso, estes pacientes eram, na sua maioria, enclausurados em grandes hospitais psiquiátricos, de modo a não perturbarem a normalidade da restante sociedade (Bentall, 1990; Bentall, 2004).

Desde a síntese dos primeiros neurolépticos, a comunidade científica tem feito sucessivos esforços, no sentido de encontrar novas e promissoras formas de tratamento desta patologia. No entanto, apesar da progressiva melhoria dos psicofármacos, muitos destes revelam-se incapazes de solucionar grande parte da sintomatologia positiva (nomeadamente, ideias delirantes, alucinações, disfunção sócio-ocupacional, agitação psicomotora, alteração do pensamento e linguagem, entre outras), em cerca de 40 por cento dos casos clínicos descritos (Haddock \& Slade, 1996). Logo, torna-se evidente que, apesar de o recurso a terapêuticas psicofarmacológicas no tratamento destes pacientes ser deveras importante, este tipo de tratamento não deve ser uma panaceia.

É necessário, por isso, o desenvolvimento de investigações de fundo que possibilitem alcançar um melhor entendimento acerca do funcionamento das pessoas que padecem desta perturbação, a par de investigações psicoterapêuticas que encontrem formas alternativas eficazes do seu tratamento, complementando as já existentes (Tarrier, Beckett, Harwood, Baker, Yusupoff \& Ugarteburu, 1993; Tarrier, Yusupoff, Kinney, McCarthy, Gledhill, Haddock \& Morris, 1998).

Assim sendo, nas últimas décadas, alguns investigadores têm salientado a pertinência de estudos que procurem compreender especificamente os sintomas da esquizofrenia (nomeadamente, as alucinações e os delírios), no sentido de favorecer o desenvolvimento de intervenções psicoterapêuticas mais eficazes (Bentall, 1990).

O estudo das ideias delirantes, mais especificamente, do tipo persecutório, tem sido alvo de grande interesse pela comunidade científica contemporânea. A razão para tamanho interesse deve-se ao facto de o conteúdo paranóide ser o mais frequentemente encontrado em pacientes delirantes. 
Maher $(1974 ; 1988)$ foi um dos primeiros teóricos da actualidade a sugerir que os delírios resultam do esforço normal da pessoa em atribuir significado a uma experiência perceptiva anómala. Este autor defende que os delírios acontecem apenas na presença e em consequência de experiências anómalas, que não derivam necessariamente de défices perceptivos. Assim, para este autor, as pessoas que sofrem de paranóia raciocinam tão racionalmente quanto quaisquer outras. Esta ideia baseia-se no facto de não se ter encontrado qualquer evidência de deficiência no raciocínio das pessoas delirantes, quando testadas através de tarefas de raciocínio silogístico. Deste modo, Maher afirma que todos os seres humanos são irracionais até determinado grau e que as pessoas delirantes não o são em maior grau (Maher, 1974; Maher, 1988).

Todavia, outras teorias contrapõem que a atribuição das ideias delirantes a um processo bottom-up ("de baixo-para cima"), como Maher alega, é insuficiente. Prova disso é exactamente o facto de que, apesar de os delírios poderem ocorrer em contexto de experiências alucinatórias e de défices perceptivos, podem ainda emergir na ausência de qualquer um destes, o que não é contemplado pela teoria de Maher. Neste sentido, esta teoria revela-se pouco útil na compreensão global deste fenómeno, já que não explica todos os casos (Garety \& Freeman, 1999).

Contrariamente à teoria de Maher $(1974 ; 1988)$, outras teorias advogam que as ideias delirantes podem ter uma explicação em termos de défice no raciocínio, de défice na capacidade de meta-representar ou ainda em termos motivacionais.

Por exemplo, uma segunda linha explicativa sugere que as ideias delirantes possam ocorrer devido a um défice, quer no processamento de informação, quer no raciocínio dos pacientes. Garety, Hemsley e Wessely (1991) pediram a participantes delirantes que fizessem estimativas probabilísticas acerca da percentagem de berlindes de duas cores diferentes existente num recipiente, depois de alguns deles terem sido retirados do mesmo. Os autores observaram que algumas pessoas com ideação paranóide (presente em quadros clínicos de esquizofrenia ou de perturbação delirante) exibiram uma tendência para saltar precipitadamente para uma conclusão, em termos de raciocínio probabilístico. Isto é, os pacientes revelaram a tendência a extrair uma conclusão explicativa, a partir duma pequena amostra de dados, de uma forma mais acentuada do que, quer os sujeitos-controlo saudáveis, quer os sujeitos-controlo psiquiátricos não-delirantes. Todavia, numa segunda investigação levada a cabo pelos mesmos autores, os pacientes com paranóia mostraram-se bastante disponíveis a mudar a sua decisão probabilística, quando postos perante alguma evidência desconfirmatória. Assim, estes resultados, apesar de indicarem a existência de um raciocínio anómalo no que concerne ao levantamento de hipóteses em indivíduos com paranóia, são 
também algo inconclusivos, lançando algumas dúvidas sobre a validade desta teoria para a explicação da paranóia (Garety et al., 1991).

Frith (1992) propôs ainda outra explicação para as ideias delirantes persecutórias e de referência. Segundo este autor, as pessoas que experimentam sintomas deste tipo possuem um défice no sistema responsável pela capacidade de inferir os estados mentais dos outros (nomeadamente, pensamentos e intenções). Ou seja, possuem uma "teoria da mente" deficitária, que as faz interpretarem erroneamente as intenções dos outros. Para tentar testar esta teoria, Corcoran, Mercer e Frith (1995) compararam o desempenho de pessoas com paranóia, participantes controlo saudáveis e participantes controlo com outras perturbações psiquiátricas, que não a esquizofrenia, numa tarefa de "teoria da mente". Apresentaram pequenas histórias aos participantes, onde duas personagens interagiam. No final de cada uma destas histórias, uma das personagens terminava, deixando uma insinuação bastante óbvia. Depois de lerem a história, os participantes eram então questionados acerca do que esta última personagem queria dizer com a tal observação indirecta. A cotação das respostas de cada participante era feita na base deste ter sido capaz de inferir acertadamente o que estava subentendido na insinuação da personagem da história. Os participantes com paranóia revelaram-se menos capazes de inferirem as intenções das personagens das histórias, quando comparados com os restantes grupos-controlo.

Curiosamente, no caso de participantes que sofreram de paranoia no passado, mas que se encontravam já recuperados na altura do estudo, não se verificou qualquer anomalia na sua capacidade de inferir as intenções dos outros, comparativamente com os restantes grupos.

No entanto, apesar de Corcoran e Frith terem encontrado resultados semelhantes noutros estudos (Frith \& Corcoran, 1996; Corcoran, Cahill, \& Frith, 1997), parece haver alguma controvérsia acerca da existência dum défice específico à paranóia na capacidade de intuir as intenções de outrem. Isto porque outros estudos se revelaram incapazes de replicar os mesmos resultados acima descritos (Sarfati et al., 1997, citados por Garety \& Freeman, 1999; Langdon et al., 1997, citados por Garety \& Freeman, 1999). Pelo contrário, na revisão crítica de Garety e Freeman (1999), na generalidade, tais estudos revelaram que os pacientes com esquizofrenia parecem apresentar uma "teoria da mente" deficitária, mais associada à presença de sintomas negativos (anedonia, passividade, entre outros), do que especificamente à existência de delírios persecutórios.

Com base nas primeiras explicações psicodinâmicas e motivacionais para a paranóia, assim como nas suas observações clínicas, Trower e Chadwick (1995) apresentam uma outra explicação para o desenvolvimento desta patologia. $\mathrm{O}$ aspecto distintivo desta teoria reside no facto de estes autores porem o enfoque principalmente no impacto que as experiências de 
infância podem ter na forma como o indivíduo expressa e raciocina sobre o mundo social, quando adulto.

Estes autores chamaram a atenção para um alegado segundo tipo de paranóia (Trower \& Chadwick, 1995; Chadwick, Birchwood \& Trower, 1996), que ainda não havia sido considerado até então e que, portanto, carecia de explicação. Para além do tipo de paranóia classicamente conceptualizado, onde a pessoa se sente imerecidamente vítima duma trama, estes autores identificaram a existência dum segundo tipo de paranóia, onde a pessoa acredita estar a ser perseguida por uma boa razão.

Deste modo, fazendo uso de abordagens psicológicas distintas, mas complementares (abordagem cognitivo-comportamental e psicanalítica), estes autores delinearam uma teoria explicativa para cada um dos dois tipos de paranóia. Segundo eles, as pessoas com paranóia do tipo "pobre de mim" (poor me paranoia - paranóia clássica) "tendem a culpar os outros, a vê-los como maus e a ver-se como vítimas" (Trower \& Chadwick, 1995, p. 265), uma vez que acreditam que os outros estão a tentar prejudicá-los sem qualquer justificação. Por outro lado, as pessoas com paranóia do tipo "eu-maldoso" (bad me paranoia) são indivíduos que "tendem a culpar-se, a ver-se como maus e a entender que os outros os tentam punir ou prejudicar com razão" (Trower \& Chadwick, 1995, p. 265), dado que acreditam que os outros conspiram contra si, devido à sua maldade. De seguida, passar-se-á a uma descrição mais pormenorizada desta teoria

\section{Teoria explicativa da paranóia de Trower e Chadwick (1995)}

Com base em intervenções clínicas e estudos empíricos, Trower e Chadwick (1995; Chadwick \& Trower, 1996; Chadwick, Birchwood \& Trower, 1996; Trower, 2003) observaram que as pessoas com paranóia tendem a percepcionar avaliações interpessoais negativas muito facilmente (i.e., avaliações dos outros ao próprio). Por outras palavras, as pessoas com paranóia tendem a acreditar que são completamente depreciadas e desvalorizadas pelos outros em geral. Para Trower e Chadwick (1995) a principal fragilidade destes pacientes reside exactamente nesta ideia negativa, da qual se julgam ser alvo por parte dos outros. Consequentemente, ao tentarem defender-se da iminente rejeição ou desvalorização externa, estas pessoas podem desenvolver modos distintos de lidar com essas fontes de ameaça ao self. De acordo com estes autores, os dois tipos de paranóia representam duas formas opostas de lidar com a ansiedade resultante da expectativa dos outros os inferiorizarem ou desvalorizarem.

Segundo Trower e Chadwick (1995) o desenvolvimento de um ou outro tipo de paranóia está condicionado pela forma como cada indivíduo lida com 
este appraisal negativo (percepção de avaliação negativa dos outros para consigo). Por um lado, perante a percepção duma avaliação negativa deste género, o indivíduo pode discordar dessa visão negativa de si mesmo e rejeitá-la. Neste caso, a avaliação resultante acerca dos outros é necessariamente, de que estes são maldosos e estão a tentar prejudicá-lo sem motivo. O indivíduo, consequentemente, concebe os outros como perseguidores e condena-os, resultando daqui o tipo de paranóia "pobre de mim".

Por outro lado, se o indivíduo concorda com a opinião crítica de que se julga ser alvo por parte dos outros, eventualmente, vê-se como merecedor do castigo destes, confirmando, assim, algum esquema negativo latente acerca de si mesmo.

Acontece, no entanto, que, no entender de Zigler e Glick (1988), a paranóia é, na realidade, uma "depressão camuflada". Se atendermos à sugestão destes autores da existência duma estreita proximidade entre a paranóia e a depressão, torna-se evidente que a compreensão da fenomenologia da primeira deverá ter em conta investigações já realizadas acerca da fenomenologia da segunda.

Neste sentido, Trower e Chadwick (1995) chamam a atenção para as crenças motivacionais (Relatedness - "Relacionalidade" - e Autonomy "Autonomia" -) distinguidas por Blatt e Zuroff (1992), no âmbito da depressão, e que, curiosamente, são semelhantes aos modos de personalidade definidos por Beck (Sociotropy - "Sociotropia" - e Autonomy - "Autonomia" -) (Beck, 1983, citado por Bieling, Beck \& Brown, 2000). Os autores propõem, assim, uma teoria explicativa para o desenvolvimento dos dois tipos de paranóia e das crenças a eles centrais, com base na distinção destas predisposições de personalidade (Trower \& Chadwick, 1995; Chadwick \& Lowe, 1994; Chadwick, Birchwood \& Trower, 1996; Dagnan, Trower \& Gilbert, 2002).

De acordo com Trower e Chadwick (1995), a paranóia do tipo "pobre de mim" diz respeito a pessoas que têm uma grande necessidade da aprovação dos outros, assim como do estabelecimento de relações de proximidade nas quais possam depender (relacionada com o modo de personalidade Sociotropy - "Sociotropia" -). Os autores prevêem que as pessoas com este tipo de paranóia valorizem em especial as relações interpessoais, uma vez que foram sujeitas a negligência ou não foram suficientemente cuidadas quando em criança. Logo, aquilo que mais temem diz respeito a um eventual abandono iminente (Trower \& Chadwick, 1995; Chadwick \& Lowe, 1994; Chadwick et al., 1996; Chadwick \& Trower, 1996; Dagnan et al., 2002).

No que concerne à paranóia do tipo "eu maldoso", esta pode ser entendida como uma forma de lidar com uma imensa necessidade de se ser aceite e apreciado pelos outros (proximamente relacionada com o modo de personalidade Autonomy - "Autonomia" -). Considera-se que este segundo tipo de paranóia deriva do facto de se ter sido sujeito a experiências de infância 
de grande desvalorização ou sobre intrusividade por parte das figuras parentais. Tais experiências podem ter instituído nestas pessoas um profundo medo de ter a sua "malvadez" descoberta pelos outros (Trower \& Chadwick, 1995; Chadwick \& Lowe, 1994; Chadwick et al., 1996; Chadwick \& Trower, 1996; Dagnan et al., 2002).

Para Blatt e Zuroff (1992), os abusos parentais para com uma criança, quer seja por negligência, quer por rejeição, sobrecontrolo, crítica ou frieza emocional, podem influenciar as representações internas desta acerca de si e dos outros. Deste modo, podem imprimir-se, num estádio muito precoce, crenças centrais negativas acerca do próprio e dos outros, as quais poderão vir a ter um papel relevante nas avaliações pessoais ulteriores, podendo conduzir à paranóia (Trower \& Chadwick, 1995).

Depois de distinguidos os dois tipos de funcionamento da paranóia conceptualizados pelos autores, as suas vulnerabilidades e os seus precursores, parece pertinente referenciar agora as suas diferentes construções do self.

\section{Construções do self na paranóia}

Trower e Chadwick (1995) sugerem que, tal como qualquer outra pessoa, as pessoas com paranóia construíram o seu self e desenvolveram estratégias defensivas para o manterem seguro de ameaças. Por outro lado, é sabido que as pessoas constroem continuamente o seu self em função das interacções que estabelecem com as figuras parentais e de referência para si. Assim, Trower e Chadwick (Dagnan et al., 2002) defendem que a forma como as outras pessoas se relacionam com o próprio e, eventualmente, as avaliações dos outros a este e deste aos outros são as responsáveis pelo desenvolvimento do self, uma vez que ajudam a moldar as auto-avaliações.

Trower e Chadwick (1995; Dagnan et al., 2002) apresentam dois tipos de self, que estão na base dos dois diferentes tipos de paranóia acima descritos. Estes autores designam de "inseguro" e "alienado/engolfado" o self das pessoas com paranóia do tipo "pobre de mim" e "eu maldoso", respectivamente.

O self "inseguro" (self presente na paranóia do tipo "pobre de mim") é concebido como sendo uma consequência da pessoa, na infância, não ter tido a oportunidade de se mostrar aos outros, quer devido a negligência, quer a rejeição. Desta experiência podem derivar sentimentos de abandono e de desvalorização, assim como expectativas de rejeição iminente por parte de outros significativos. Por essa razão, os autores defendem que a crença de se ser o centro da atenção dos outros pode ajudar a pessoa a compensar uma necessidade narcísica latente (que se julga acontecer nas pessoas com paranóia do tipo "pobre de mim"). Esta última pode ter sido desenvolvida a partir 
da ausência da oportunidade de se "ser" realmente. Assim, perante as avaliações negativas dos outros, o indivíduo com um self "inseguro" prefere interpretá-las como uma perseguição, em vez de reconhecê-las como mais uma rejeição ou indiferença.

Pelo contrário, o self "alienado/engolfado" (self das pessoas com paranóia do tipo "eu-maldoso") pode resultar dum excesso de controlo e intrusão que constrange o indivíduo a sentir-se encurralado e, portanto, a temer grandemente a intrusão dos outros. Neste caso, é possível que o self construído não seja autêntico (falso self). Este tipo de self envolve sentimentos de vergonha e de inferioridade, visto que a pessoa, quando criança, foi constantemente exposta a críticas hostis e à intrusão dos outros. Neste sentido, a pessoa com um self "alienado" procura não só escapar da pressão crítica e das intromissões dos outros, mas, principalmente, procura esconder destes a sua fraqueza e malvadez. Tal pode ser conseguido através do desenvolvimento dum delírio persecutório do tipo "eu-maldoso".

Em suma, Trower e Chadwick (1995) defendem que os dois tipos de paranóia e os seus respectivos self podem estar associados a experiências de infância. Estas, por sua vez, podem ter contribuído para que os indivíduos se percepcionem como alvo de avaliações negativas e depreciativas por parte dos outros. Mais, tais experiências de infância podem acontecer num contexto familiar demasiado crítico, intrusivo e desaprovador (paranóia do tipo "eu-maldoso"), ou podem, ainda, ocorrer a partir dum estilo parental demasiado rejeitante e negligente (paranóia do tipo "pobre de mim"). De acordo com Trower e Chadwick (1995), os dois diferentes tipos de delírios persecutórios servem o propósito de satisfazer diferentes necessidades desenvolvidas em infância: de aprovação (paranóia do tipo "eu-maldoso") e de apreciação (paranóia do tipo "pobre de mim").

Bentall, Corcoran, Howard, Blackwood e Kinderman (2001) propuseram recentemente um modelo integrativo para explicar a paranóia, que e no fundo uma adaptacao do modelo inicial de Bentall, Kinderman e Kaney (1994). Esta nova linha de pensamento recorre à combinação de teorias motivacionais e de processamento cognitivo de informação, para explicar a génese e a manutenção de delírios persecutórios.

\section{Modelo de Auto-Representação Atribucional (Bentall et al., 2001)}

Bentall et al. (1994) defendem que, apesar de as pessoas com paranóia terem desenvolvido um sistema de crenças anómalo (um sistema delirante), tal foi alcançado de forma semelhante a qualquer outra crença e a qualquer outra pessoa. No entanto, os autores advogam que, no caso da ideação persecutória, parece haver uma necessidade subjacente de percepcionar a reali- 
dade, de tal forma que as outras pessoas são vistas como deliberadamente maldosas. As pessoas com paranóia são assim capazes de atribuir os seus infortúnios a causas exteriores, protegendo a sua auto-estima.

Esta conceptualização parte do pressuposto inicialmente avançado por Colby, Faught e Parkinson (1979) de que os delírios persecutórios resultam dum processo psicológico de defesa contra as ameaças ao self. A partir deste pressuposto, espera-se que as pessoas que mantêm delírios persecutórios possuam também crenças negativas latentes acerca de si mesmas. Nesta linha de pensamento, faz, portanto, sentido pressupor que estas pessoas tenham uma auto-estima latente muito baixa, que este mecanismo de defesa procura compensar.

Candido e Romney (1990) pediram a indivíduos com depressão e a indivíduos com paranóia que respondessem a um questionário de auto-relato de auto-estima. Os autores observaram que os indivíduos com paranóia expressaram níveis de auto-estima bastante mais elevados do que os indivíduos com depressão. Num estudo realizado por Lyon, Kaney e Bentall (1994), os pacientes delirantes revelaram possuir uma auto-estima tão elevada quanto os sujeitos-controlo saudáveis.

Bentall e Kaney (1996) avaliaram a auto-estima de indivíduos com paranóia e de indivíduos com depressão de duas formas distintas: através duma tarefa explícita/"aberta" (onde lhes era pedido que escolhessem, duma lista de adjectivos, aqueles que os caracterizavam) e duma medida indirecta/"fechada" (onde os sujeitos tinham de recordar o maior número de adjectivos da lista anteriormente apresentada). Os indivíduos com paranóia, apesar de se caracterizarem principalmente como possuíndo características positivas, tenderam a recordar-se maioritariamente de adjectivos negativos, de modo semelhante aos indivíduos depressivos.

No entanto, Freeman, Garety, Fowler, Kuipers, Dunn, Bebbington e Hadley (1998) estudaram longitudinalmente (durante um período de 18 meses) a auto-estima de indivíduos com delírios persecutórios e sujeitos-controlo saudáveis e observaram que, a maioria dos primeiros apresentaram uma auto-estima inferior à dos segundos.

Ainda que este último estudo tenha encontrado resultados inconsistentes, a maioria dos estudos dá indicação de que, apesar das tremendas dificuldades de vida com as quais as pessoas que sofrem de paranóia habitualmente se confrontam, estas conseguem manter uma auto-estima elevada a tudo o custo (Bentall \& Kaney, 1996).

Sendo isto verdade, é provável que as pessoas com paranóia tenham auto-representações latentes negativas, de modo semelhante às pessoas com depressão, embora procurem activamente ocultá-las da sua consciência. Curiosamente, esta ideia da existência duma similitude entre os esquemas cognitivos das pessoas com paranóia e com depressão, inicialmente avan- 
çada por Zigler e Glick (1988), é um aspecto acerca do qual, quer o modelo de Bentall et al. (2001), quer a teoria explicativa da paranóia, proposta por Trower e Chadwick (1995), estão em concordância.

No entanto, Bentall et al. (1994) vão mais longe e chamam a atenção para o facto de que a diferença entre as pessoas com paranóia e depressão reside precisamente num viés de autovalorização, presente nas pessoas com paranóia (mas ausente nas pessoas depressivas), que serve o propósito de encobrir a sua baixa auto-estima, de modo a diminuir a discrepância entre a sua imagem ideal e auto-imagem.

Ainda assim, seria de esperar que as pessoas com paranóia tendessem a adoptar este mecanismo autoprotector por responsabilização externa, não apenas no que diz respeito aos temas relacionados com o delírio persecutório, mas também como uma estratégia geral aplicável a quaisquer situações diárias, protegendo, deste modo, a sua auto-estima em vários contextos de vida.

Num estudo inicial de Kaney e Bentall (1989) onde se compararam as respostas ao Questionário de Estilo Atribucional (ASQ) de indivíduos com paranóia, de indivíduos com depressão e de participantes saudáveis - estudo esse que foi posteriormente replicado, com resultados semelhantes, por Candido e Romney (1990) - constactou-se a existência dum estilo atribucional anómalo em participantes com paranóia. Ou seja, a maioria dos participantes com paranóia mostraram possuir um viés de auto-valorização, que os impelia a atribuírem os acontecimentos positivos à sua própria responsabilidade e os negativos a pessoas exteriores, de forma mais exagerada do que o viés habitualmente encontrado na população normal (Hewstone, 1989, citado por Kaney \& Bentall, 1992; Zuckerman, 1979, citado por Kaney \& Bentall, 1992; Kinderman e Bentall, 1996). De igual modo, estudos posteriores conduzidos por Kaney e Bentall (1992) e Sharp, Fear e Healy (1997) reiteraram estas conclusões.

Assim, as pessoas com delírios persecutórios parecem ser altamente susceptíveis a ameaças ao seu auto-conceito (Kaney \& Bentall, 1989; Candido \& Romney, 1990; Kaney \& Bentall, 1992; Lyon, Kaney \& Bentall, 1994). No sentido de prevenir que um acontecimento negativo accione uma crença pessoal negativa latente, o indivíduo pode fazer uso dum processo de defesa psicológico: o viés atribucional de auto-favorecimento. Este viés atribucional observado nestas pessoas pode também explicar a razão pela qual elas desenvolvem delírios persecutórios e porque tentam preservá-los a todo o custo. Ao assumir que os outros são merecedores de um qualquer acontecimento de vida negativo, a pessoa que possui uma ideia persecutória evita a autoresponsabilização, mantendo, deste modo, um elevado nível de auto-estima (Bentall \& Kaney, 1994; Kinderman \& Bentall, 1996; Bentall et al., 2001). 
Bentall et al. $(1994 ; 2001)$ defendem, portanto, que os processos atribucionais de causalidade são centrais ao desenvolvimento e à manutenção dos delírios persecutórios, uma vez que estes processos socio-cognitivos entram em jogo em situações diárias, quando a pessoa atribui significado a uma qualquer situação e justifica a sua causa.

Em todo o caso, Bentall et al. (2001) acreditam que este processo não acontece num só sentido, onde apenas as auto-representações influenciam as atribuições causais. Para estes autores, as atribuições e as auto-representações retro-alimentam-se, interagindo ciclicamente. Pressupõem, por isso, que o efeito que uma atribuição de causalidade tem na saliência duma auto-representação no presente não só afecta a saliência desta última num futuro próximo, como também influenciará subsequentes atribuições, as quais, por sua vez, afectarão as crenças pessoais iniciais da pessoa. Os autores designaram este ciclo de Auto-Representação Atribucional.

Kinderman e Bentall (2000) procuraram testar empiricamente este modelo, tentando perceber até que ponto o auto-conceito e os processos de atribuição causal têm implicações recíprocas e dinâmicas um no outro e afectam directamente o estado de humor da pessoa. Neste estudo, os autores evidenciaram que o priming (apresentação inicial dum estímulo) de atribuições causais internas de situações negativas tendia a aumentar a discrepância entre as autopercepções actuais (auto-imagem) e as ideais (imagem-ideal). Os autores observaram ainda um aumento da discrepância entre as autopercepções actuais e as percepções actuais que a pessoa julga que os outros têm acerca de si, na condição de priming de atribuições causais pessoais externas. Verificou-se, no entanto, que este priming tendia a diminuir a discrepância entre a auto-imagem ideal e actual. Mais, constatou-se, ainda, que as atribuições situacionais externas estavam associadas à diminuição da acessibilidade de ambos os tipos de discrepância.

Os resultados deste estudo são consistentes com o modelo de Bentall et al. (2001), dado que revelam que as pessoas com delírios persecutórios podem possuir um viés cognitivo, no sentido de atribuírem acontecimentos negativos a causas pessoais externas (especialmente às acções dos outros) como um mecanismo auto-protector. Os participantes-controlo saudáveis, que supostamente não possuem esquemas cognitivos latentes excessivamente negativos, parecem preferir atribuir a causa dos acontecimentos negativos exteriormente, mas situacionalmente, embora este processamento seja cognitivamente mais exigente.

Mais recentemente, Martin e Penn (2002) compararam o estilo atribucional de causalidade de dois grupos de indivíduos delirantes: indivíduos com delírios persecutórios, indivíduos com delírios não-persecutórios e sujeitos-controlo saudáveis, em três medidas diferentes de atribuição de causalidade. Os autores não encontratam qualquer diferença entre as atribuições 
de, quer ambos os grupos de indivíduos delirantes, quer os sujeitos controlo normais, em duas das três medidas de atribuição de causalidade. Tais resultados levantam aparentemente algumas dúvidas acerca da validade do modelo de Bentall et al. (2001) na explicação da paranóia. No entanto, Martin e Penn (2202) encontraram ainda uma correlação entre o número de atribuições externas pessoais e a presença de delírios persecutórios, conforme previsto pelo modelo de Bentall et al. (2001).

No que diz respeito à paranóia do tipo "eu-maldoso", o modelo de Bentall et al. (2001), na sua mais recente adaptação, já contempla essa possibilidade. A paranóia do tipo "eu-maldoso" pode ser explicada como proveniente duma falha no mesmo processo defensivo descrito inicialmente para o caso da paranóia do tipo "pobre de mim" (numa tentativa de proteger a auto-estima, mantendo-a elevada). Por outras palavras, a paranóia do tipo "eu-maldoso" pode surgir quando os esquemas negativos duma pessoa são activados a partir de situações negativas por ela vividas, de forma que a mesma tem dificuldade em fazer uso de atribuições causais externas nas situações subsequentes.

Melo, Taylor e Bentall (2006) tentaram testar empiricamente ambos estes modelos, estudando as diferenças entre a paranóia do tipo "pobre de mim" e "eu-maldoso". Para tal, compararam as respostas a um conjunto de medidas psicológicas de traço (PBI; PSI; SOS e $A S Q)$ e situacionais (DEI e $B D I)$ de indivíduos com delírios persecutórios do tipo "pobre de mim" e do tipo "eu-maldoso" e de sujeitos-controlo saudáveis. A atribuição dos participantes delirantes a cada um dos grupos clínicos foi feita com base nas suas respostas à Escala de Percepção de Merecimento da Perseguição, desenvolvida pelos autores.

Melo et al. (2006) observaram que, durante o decorrer do estudo, cerca de trinta e cinco porcento da amostra clínica transitou de um tipo de paranóia para o outro. Logo, os autores defendem que, ao contrário do que a teoria de Trower e Chadwick (1995) prevê, a percepção de merecimento da perseguição pode variar ao longo do tempo. Assim, em vez da paranóia "pobre de mim" e "eu-maldoso" serem dois tipos de paranóia distintos, Melo et al. (2006) propõem que estamos perante duas fases distintas de um mesmo fenómeno, que é por natureza instável e dinâmico. Mais, não se encontraram quaisquer diferenças entre os grupos clínicos no que diz respeito às medidas psicológicas de traço que a teoria de Trower e Chadwick (1995) prevê. Conforme sugerido quer pelo modelo de Bentall et al. (2001), quer pela teoria de Trower e Chadwick (1995), a maioria dos indivíduos com delírios persecutórios do tipo "pobre me mim" atribuíram a responsabilidade de acontecimentos negativos a causas externas, mas o mesmo não se verificou nos indivíduos com a paranóia do tipo "eu-maldoso" e, estes últimos, mostraram-se bastante mais depressivos do que os primeiros. 
Assim, de uma forma geral, o modelo de Auto-Representação Atribucional de Bental et al. (2001) parece proporcionar um melhor entendimento dos resultados encontrados por Melo et al. (2006). Isto porque, aquele modelo pressupõe a existência dum processo dinâmico na base do qual o desenvolvimento e a manutenção da paranóia é permeavel às situações de vida pelas quais os indivíduos se vêem confrontados, podendo a percepção de merecimento da perseguição variar com o tempo.

Mais investigações de fundo, que testem o modo através do qual estes processos são conduzidos, quer em termos de flutuações da auto-estima e do auto-conceito destes pacientes, quer em termos de flutuações da percepção de merecimento da perseguição em relação a acontecimentos de vida, permitirão, seguramente, uma melhor compreensão do desenvolvimento, mas principalmente, do dinamismo intrínseco à paranóia.

\section{Referências}

Bentall, R. P. (1990). The syndromes and symptoms of psychosis: Or why you can't play 20 questions with the concept of schizophrenia and hope you can't win. In R. P. Bentall (Ed.), Reconstructing schizophrenia (pp. 23-60). London: Routledge.

Bentall, R. P. (2004) Madness explained: Psychosis and man nature. Penguin Books: London.

Bentall, R. P., Corcoran, R., Howard, R., Blackwood, R., \& Kinderman, P. (2001). Persecutory delusions: A review and theoretical integration. Clinical Psychology Review, 21, 1143-1192.

Bentall, R. P., Kaney, S. (1996). Abnormalties of self-representation and persecutory delusions: a test of cognitive model of paranoia. Psychological Medicine, 26, 1231-1237.

Bentall, R. P., Kinderman, P., \& Kaney, S. (1994). The self, attributional processes and abnormal beliefs: Towards a model of persecutory delusions. Behaviour Research and Therapy, 32, 331-341.

Bieling, P. J., Beck, A. T., \& Brown, G. K. (2000). The Sociotropy-Autonomy Scale: Structure and implications. Cognitive Therapy and Research, 24, 763-780.

Blatt, S. J., \& Zurroff, D. C. (1992). Interpersonal relatedness and self-definition: Two prototypes for depression. Clinical Psychology Review, 12, 527-562.

Candido, C. L., \& Romney, D. M. (1990). Attributional style in paranoid vs. depressed patients. British Journal of Medical Psychology, 63, 355-363.

Carpenter, W. T., \& Strauss, J. S. (1991). The prediction of outcome in schizophrenia.

IV: Eleven-year follow-up of a Washington IPSS cohort. Journal of Nervous and Mental Disease, 179, 517-25.

Chadwick, P., Birchwood, M., Trower, P. (1996b) Cognitive Therapy for Delusions, Voices and Paranoia. Chichester: Wiley. 
Chadwick, P. D. J., \& Lowe, C. F. (1994). A cognitive approach to measuring and modifying delusions. Behaviour Research and Therapy, 32 (3), 355-376.

Chadwick, P.; \& Trower, P. (1996). Cognitive therapy for punishment paranoia: a single case experiment. Behaviour Research and Therapy, 34 (4), 351-356.

Colby, K. M.; Faught, W. S.; Parkinson, R. C. (1979). Cognitive therapy of conditions: Heuristic suggestions based on a computer stimulation model. Cognitive Therapy and Research, 3 (1), 55-60.

Corcoran, R., Cahill, C. \& Frith, C. D. (1997). The appreciation of visual jokes in people with schizophrenia: A study of 'mentalizing' ability. Schizophrenia Research, 24, 319-327.

Corcoran, R., Mercer, G. \& Frith, C. D. (1995). Schizophrenia, symptomatology and social inference: Investigating 'theory of mind' in people with schizophrenia. Schizophrenia Research, 17, 5-13.

Dagan, D., Trower, P. \& Gilbert, P. (2002). Measuring vulnerability to threats to self-construction: The Self and Other Scale. Psychology and Psychotherapy: Theory, Research and Practice, 75, 279-293.

Freeman, D., Garety, P., Fowler, D., Kuipers, E., Dunn, G., Bebbington, P., \& Hadley, C. (1998). The London-East Anglia randomized controlled trial of cognitive-behaviour therapy for psychosis IV: Self-esteem and persecutory delusions. British Journal of Clinical Psychology, 37, 415-430.

Frith, C. D. (1992). The cognitive neuropsychology of schizophrenia. Hove: Lawrence Erlbaum.

Frith, C. D., \& Corcoran, R., (1996). Exploring the 'theory of mind' in people with schizophrenia. Psychological Medicine, 26, 521-530.

Garety, P. A., Hemsley, D. R., \& Wessely, S. (1991). Reasoning in deluded schizophrenic and paranoid patients. Journal of Nervous and Mental Disease, 179 (4), 194-201.

Garety, P., \& Freeman, D. (1999). Cognitive approaches to delusions: A critical review of theories and evidence. British Journal of Clinical Psychology, 38, 113-154.

Haddock, G. \& Slade, P. (1996). Cognitive-behavioural interventions with psychotic disorders. Routledge Publishers: London and New York.

Kaney, S., \& Bentall, R. P. (1989). Persecutory delusions and attributional style. British Journal of Medical Psychology, 62, 191-198.

Kaney, S., \& Bentall, R. P. (1992). Persecutory delusions and the self-serving bias. Journal of Nervous and Mental Disease, 180, 773-780.

Kinderman, P., \& Bentall, R. P. (2000). Self-discrepancies and causal attributions: Studies of hypothesized relationships. British Journal of Clinical Psychology, 39, 255-273.

Kinderman, P., \& Bentall, R. P. (1996). Self-discrepancies and persecutory delusions: Evidence for a defensive model of paranoid ideation. Journal of Abnormal Psychology, 105, 106-114.

Lyon, H. M., Kaney, S., \& Bentall, R. P. (1994). The defensive function of persecutory delusions: Evidence from attribution tasks. British Journal of Psychiatry, 164, 637-646. 
Maher, B. A. (1988). Anomalous experience and delusional thinking: The logic of explanations. In T. F. Maher \& B. A. Maher (Eds.), Delusional beliefs (pp. 15-33). New York: Wiley.

Maher, B. A. (1974). Delusional thinking and perceptual disorder. Journal of Individual Psychology, 30, 98-113.

Martin, J. A., \& Penn, D. L. (2002). Attributional style in schizophrenia: An investigation in outpatients with and without persecutory delusions. Schizophrenia Bulletin, 28, 131-142.

Melo, S. S., Taylor, J. L., \& Bentall, R. P. (2006). 'Poor me' vs. 'Bad me' paranoia: the instability of persecutory ideation. Psychology and Psychotherapy: Theory, Research and Practice, 79, 271-287.

Sharp, H. M., Fear, C. F., \& Healy, D. (1997). Attributional style and delusions: An investigation based on delusional content. European Psychiatry, 12, 1-7.

Tarrier, N., Beckett, R., Harwood, S., Baker, A., Yusupoff, L., \& Ugarteburu, I. (1993). A trial of two cognitive-behavioural methods of treating drug-residual psychotic symptoms in schizophrenic patients: outcome. British Medical Journal of Psychiatry, 162, 524-532.

Tarrier, N., Yusupoff, L., Kinney, C., McCarthy, E., Gledhill, A., Haddock, G., \& Morris, J. (1998). Randomized controlled trial of intensive cognitive behaviour therapy for patients with chronic schizophrenia. British Medical Journal, 317, 303-307.

Trower, P., \& Chadwick, P. (1995). Pathways to defense of the self: A theory of two types of paranoia. Clinical psychology: Science and practice, 2, 263-278.

Trower, P. (2003). Theoretical developments in REBT as applied to schizophrenia. In W. Dryden (Ed.), Rational emotive behaviour therapy. New York: Brunner-Routledge.

Zigler, E., \& Glick, M. (1988). Is paranoid schizophrenia really camouflaged depression? American Psychologist, 43, 284-290. 